\title{
Voltage Sag, Voltage Swell and Harmonics Reduction Using Unified Power Quality Conditioner (UPQC) Under Nonlinear Loads
}

\author{
Ahmed Yahyia Qasim*1,2, Fadhil Rahma Tahir ${ }^{1}$, Ahmed Nasser B. Alsammak ${ }^{3}$ \\ ${ }^{1}$ Electrical Engineering Department, University of Basrah, Basrah, Iraq \\ ${ }^{2}$ Ministry of Industry and Minerals, SDI, Mosul, Iraq \\ ${ }^{3}$ Electrical Engineering Department, University of Mosul, Mosul, Iraq.
}

\begin{abstract}
Correspondence
* Ahmed Yahyia Qasim

Electrical Engineering Department,

University of Basrah, Basrah, Iraq.

Email: ahatim2019@gmail.com
\end{abstract}

\begin{abstract}
In light of the widespread usage of power electronics devices, power quality $(P Q)$ has become an increasingly essential factor. Due to nonlinear characteristics, the power electronic devices produce harmonics and consume lag current from the utility. The UPQC is a device that compensates for harmonics and reactive power while also reducing problems related to voltage and current. In this work, a three-phase, three-wire UPQC is suggested to reduce voltage-sag, voltage-swell, voltage and current harmonics. The UPQC is composed of shunt and series Active Power Filters (APFs) that are controlled utilizing the Unit Vector Template Generation (UVTG) technique. Under nonlinear loads, the suggested UPQC system can be improved PQ at the point of common coupling (PCC) in power distribution networks. The simulation results show that UPQC reduces the effect of supply voltage changes and harmonic currents on the power line under nonlinear loads, where the Total Harmonic Distortion (THD) of load voltages and source currents obtained are less than 5\%, according to the IEEE-519 standard.
\end{abstract}

KEYWORDS: Voltage-sag, Voltage-swell, Power system, Harmonics, UPQC.

\section{NOMENCLATURE}

$\mathrm{V}_{\text {sabc }}$

$\mathrm{V}_{\text {Lab }}$

$\mathrm{V}_{\mathrm{m}}$

$\mathrm{V}_{\text {se }}$

$\mathrm{V}_{\mathrm{dc}}$

$\mathrm{V}_{\mathrm{abc}}$

$\mathrm{V}^{*}{ }_{\mathrm{dc}}$

$\mathrm{V}^{*}$ Labc

$\mathrm{I}_{\mathrm{sabc}}$

I $^{*}$ sabc

ILabc

$\mathrm{I}_{\mathrm{sh}}$

$\mathrm{Im}_{\mathrm{m}}$

$\mathrm{L}_{\text {se }}$

$\mathrm{C}_{\text {se }}$

$\mathrm{C}_{\mathrm{dc}}$

$\mathrm{L}_{\mathrm{sh}}$

$\omega t$

UPQC

THD

DDC

UVTG

PLL

PCC
Source voltage

Load voltage

Peak amplitude of fundamental supply voltage

Series injected voltage

DC capacitor voltage

Unity terminal voltage

Reference DC capacitor voltage

Reference load voltage

Source current

Reference source current

Load current

Shunt injected current

Peak amplitude of fundamental supply current

Filter inductor of series APF

Filter capacitor of series APF

DC-link capacitor

Shunt inductor

Phase angle for source voltage

Unified Power Quality Conditioner

Total Harmonic Distortion

Data-driven control

Unit Vector Template Generation

The phased locked loop

The point of common coupling

$\begin{array}{ll}\text { APF } & \text { Active Power Filter } \\ \text { DVR } & \text { Dynamic Voltage Restorer } \\ \text { EPLL } & \text { enhanced PLL } \\ \text { VSC } & \text { Voltage source converter } \\ \text { WES } & \text { Wind energy system } \\ \text { VSI } & \text { Voltage source inverter } \\ \text { SRF } & \text { Synchronous reference frame } \\ \text { CSC } & \text { Current source converters } \\ \text { MC-UPQC } & \text { Multi converter UPQC } \\ \text { UPQC-MD } & \text { Modular UPQC } \\ \text { UPQC-O } & \text { Open UPQC } \\ \text { IUPQC } & \text { Interline UPQC } \\ \text { PAC } & \text { Phase angle control } \\ \text { DG } & \text { Distributed generation } \\ \text { PQ } & \text { Power quality } \\ \text { ANN } & \text { Artificial neural network } \\ \text { LPF } & \text { Low pass filter } \\ \text { ANFIS } & \text { Adaptive-neuro-fuzzy-interference-system }\end{array}$

\section{INTRODUCTION}

Modern electric power systems are plagued by problems with power quality (PQ). Voltage sag, voltage swell, transient, frequency deviation, flicker, harmonics in voltage and current, and zero sequence current are the major problems with PQ [1]. The term "electric PQ" refers to 
maintaining the near-sinusoidal waveform of voltages and currents on the distribution bus at the rated magnitude and frequency. The ratio of nonlinear loads such as transformers, electric furnaces, and electric and electronic equipment is rapidly increasing as the power system develops. Nonlinear loads linked to PCC cause system PQ distortion, which pollutes the power supply environment [2]. Voltage distortion will harm higher costly electrical devices and the losses are increasing in a system [3]. The UPQC is based on a converter circuit that is used to alleviate PQ problems. The UPQC can be established to protect sensitive loads inside the plant and to prevent any distortion from entering from the load side. The UPQC is one of the most appropriate devices for tackling both consumer and utility issues because of its dual purpose [4][5]. The UPQC consists of a cascade of series and shunt inverters linked by a common DC-link capacitor. A UPQC's main function is to compensate for voltage sag, swell, and imbalance, as well as reactive power, negative-sequence voltage/current, and harmonics [6] [7].

In (1998) Fujita and Akagi introduced the first practical implementation of UPQC, using a shunt APF and a series APF with a common DC link [8]. Many researchers have studied this device since then and developed a variety of topologies, models, and control methods for it.

In (2003) Luis F.C. Monteiro and et al. proposed a UPQC control technique in 3-phase 3-wire systems. This control strategy is intended to Control the shunt inverter which ensure balanced, sinusoidal, and decreased supply currents even when the voltages of system are unbalanced and/or distorted, also recognized as "Sinusoidal Fryze Currents". After then, a dual control mechanism for series inverter was evolved utilizing this control approach. The recommended control technique has been validated by the simulation results [9].

In (2004) Min-Sung Yun, and et al. employed a min power injection algorithm to control a UPQC-Q. With the series compensator's rating limited, the traditional UPQC can't adequately compensate for voltage sag. When the rating is limited, the suggested control technique can efficiently and economically compensate for voltage sag while using the least amount of active power. The suggested control technique can efficiently and economically compensate for voltage sag while using minimum of effective power [10].

In (2005) Y. Y. Kolhatkar and et al. proposed and analyzed a three-phase UPQC with an upgraded a Dynamic Voltage Restorer (DVR) topology. For voltage sag with minimal imbalance or no unbalance, UPQC works in minimum VA optimization mode. To improve tracking performance, the DVR with sliding-mode control is used. In addition, it regulates the load voltage, ensuring that the overall UPQC is loaded with the minimal possible of VA, by injecting voltage at the optimal angle [11].

In (2006) B. Han and et al. proposed a new (UPQCMD) configuration that can be connected to the distribution system without the need of series injection transformers. Each phase is made up of numerous pairs of $\mathrm{H}$-bridge modules that are isolated by 1-ph multi-wound transformer (shunt side). By increasing the number of $\mathrm{H}$-bridge modules, the Modular UPQC is possible to boost the voltage of operation. The suggested UPQC might be able to improve
PQ at the place of installation on the power distribution system [12].

In (2007) Amit Kumar Jindal and et al. suggested a novel connection for UPQC, where known an interline UPQC (IUPQC) due to that the UPQC is connected to two various feeders. It's utilized in a distribution system to improve the PQ of two feeders. This device would be demonstrated linked between two different feeders to control the bus voltage of one feeder while adjusting the voltage across a susceptible load in the else feeder. The IUPQC's performance was tested under a variety of disturbance situations, including voltage-sag in either feeder, a problem in one of the feeders, and load changes [13].

In (2008) Vinod Khadkikar and et al employed a new 3phase UPQC for load-reactive power demand compensation. For load-reactive power compensation, most UPQC-based systems use a shunt inverter, whereas the series inverter is always thought of as a regulated voltage source capable of treating all voltage-related problems. A novel UPQC feature called phase angle control (PAC) of UPQC is described in this work, in which the load-reactive power requirement is met by both shunt and series APFs. This function not only assists in distributing load-reactive power demand, but it also aids in lowering the shunt inverter rating and hence the total UPQC cost [14].

In (2009) Hamid Reza Mohammadi and et al. proposed a new UPQC system for multi-bus/multi-feeder systems that can compensate both current and voltage at the same time. The new arrangement is known as Multi-converter UPQC (MC-UPQC). In this design, there is one shunt voltagesource converter (shunt VSC) and two or more series VSCs. On the dc side, all converters in the proposed configuration are interconnected and sharing a joint dc-link capacitor. As a consequence, power may be transferred from one feeder to nearby feeders to compensate for sag/swell and interruption [15].

In (2010) Yash Pal and et al. given two topologies to improve PQ problems in a three-phase, four-wire distribution system. In this work, they compare these topologies to the most commonly four-leg VSI-based 4-wire UPQC architecture. For various PQ issues such as voltage harmonic alleviation, current Harmonic abatement, load balancing, power factor correction, and source neutral current mitigation, the performance of each UPQC topology is examined [16].

In (2011) M. Kesler and et al. described a modern SRFbased control technique employed in the UPQC, under unbalanced load current and non-ideal source voltage situations, which primarily compensates current and voltage harmonics besides to reactive power. The proposed control approach for series APF uses just loads and source voltage measurements on the basis of a synchronous reference frame (SRF) method. The traditional techniques need the measurement of supply, load and filter currents for the shunt inverter, while the series inverter requires measure source and injection voltage. The simulation outcome shows that when the load is distorted and imbalanced, the series inverter separated the loads and supply voltage, on the other hand, the shunt inverter compensate for harmonics, neutral-current, 
and reactive-power together with supplying 3-phase balanced and rated mains currents [17].

In (2012) Pedro E. Melín and et al. proposed utilizing current source converters (CSC) to create a three-phase unified power quality conditioner (CSC-UPQC), which includes important component design guidelines and an appropriate control scheme, where CSC forms a dc link by sharing an energy storage inductor. In terms of voltage disturbance compensation in $\mathrm{PCC}$ and load power factor correction, the CSC-UPQC is similar to a UPQC based on voltage-source converters [18].

In (2013) Shafiuzzaman K Khadem and et al. proposed a novel idea for installing and integrating UPQC in DGlinked microgrid/micro generation systems. Throughout the interconnected mode, the proposed UPQC $\mu \mathrm{G}$ has the benefit of compensating voltage interruptions, voltage sags/swells, harmonics and reactive power compensation. The DG Converter with storing will only provide active power in the island mode, whilst the UPQC's shunt part will compensate for the load's reactive power and harmonics. Therefore, the system can operate in both connected and isolated modes. The outcomes show that the suggested system can compensate for voltage troubles in the PCC, and also the load's reactive and harmonic currents [19].

In (2014) A. Jeraldine Viji and et al. devised an enhanced phased locked loop (PLL)-based SRF control method that is utilized in UPQC to recompense reactivepower, as well as voltage and current harmonics, when the current in load is unbalanced. The SRF approach is used to extract the fundamental source voltages and currents in both APFs. EPLL enables for the generation of reference current even when the load state is distorted. The modeling and experiment outcomes show that the control goals have been met [20].

In (2015) Mihir Hembram and et al. examined a hysteresis current and voltage controller-based control approach for UPQC. The UPQC's series and shunt APFs are controlled in this design by a blending of UVTG and instantaneous $\mathrm{p}-\mathrm{q}$ method. With the use of two different control techniques, the results show that source voltage harmonics, source voltage sag/swell, and load current harmonics may all be easily done [21].

In (2016) Jian Ye and et al. established a technique for calculating the optimal UPQC size based on compensation demands. UPQC system size may be optimized by using a generalized method based on the fundamental ratings of the series converter, shunt converter, and series transformer, which are all defined by the fundamental ratings. As a result of the data-driven control (DDC) technique, the developed UPQC system may be executed under varied compensating situations. System safety is ensured by the DDC-based controller, which reduces UPQC VA load and ensures safe operation. [22].

In (2017) Shubh Lakshmi and et al. devised a technique to incorporate the open UPQC (UPQC-O) to progress the PQ and energy loss. In this technique, neither the shunt nor the series inverters were connected to a (DC)-link. For reactive power compensation and harmonics removal, the shunt inverter is employed. All downstream loads are protected from voltage-sag, and under healthy conditions, reactive power compensation is provided by the series inverter [23].

In (2018) Shubh Lakshmi and et al. designed four different UPQC models to ameliorate the energy efficiency of radial distribution networks. To find the optimal locations for the series and shunt inverters, a planned optimization model is evolving for these four models. Costs associated with inverters and batteries, as well as energy loss are included in the objective function [24].

In (2019) T. M. Thamizh Thentral and et al. designed UPQC system has ten switches, which providing best performance than traditional 12-switch UPQC systems. In order to operate a UPQC with less switches, SRF-based carrier double zero sequence signal modulation method is employed. Different PQ problems in voltage and current waveforms, including as voltage sag, current ripples, and THD, can be reduced with this technique [25].

In (2020) Parul Chaudhary and et al. introduced an enhanced fuzzy-based MC-UPQC to improve the gridconnected wind energy systems' power quality. MC-UPQC with hybrid fuzzy incremental conductance control is new in this work. When used in conjunction with MC-UPQC, the suggested controller ameliorates the WES from a grid perspective. The MC-UPQ is designed to avoid voltage imbalance problems such as voltage sag and swell as well as interruption and harmonics [26].

In (2021) Manivasagam Rajendran proposed four intelligent control approaches to improve UPQC device PQ. As part of the comparative research, the effectiveness of the anticipated approach was evaluated using artificial neural network (ANN) controllers, fuzzy logic controllers, neurofuzzy controllers, and adaptive neuro-fuzzy interference systems (ANFIS). Searchers praised the ANFIS-UPQC technique for its skilled and strength in influencing control discussion frameworks. [27].

In this paper, in part II, we describe the system architecture that we are evaluating. While section III explains the suggested method of control based on UVTG. Section VI discusses the MATLAB/Simulink simulation findings, and section $\mathrm{V}$ ends the work.

\section{Configuration OF UPQC}

The UPQC system Schematic is illustrated in Fig.1. The system is a three-phase, three-wire AC system. A common dc link connects two voltage source inverters (VSIs). It basically consists of [28]:

1. Series (VSI) - The series APF is the inverter connected in series to the utility supply. It is considered a voltage-source that reduces voltage disturbances..

2. Shunt (VSI) - It is known as a shunt active power filter, where it is connected to the network in shunt. This inverter removes the current-harmonics and reduces the reactive current in the load.

3. DC-link capacitor - It uses as common DC-link. The two inverters get DC voltage from this capacitor.

4. LC filter - The switching ripples are produced in the output of the series inverter. The LC filter decreases the amount ripples in the system. It works as a LPF. 
5. Lsh (shunt) Filter - During switching process the ripples are reduced via Lsh filter.

6. Injection transformer - It connects the series-inverter to the Ac line.

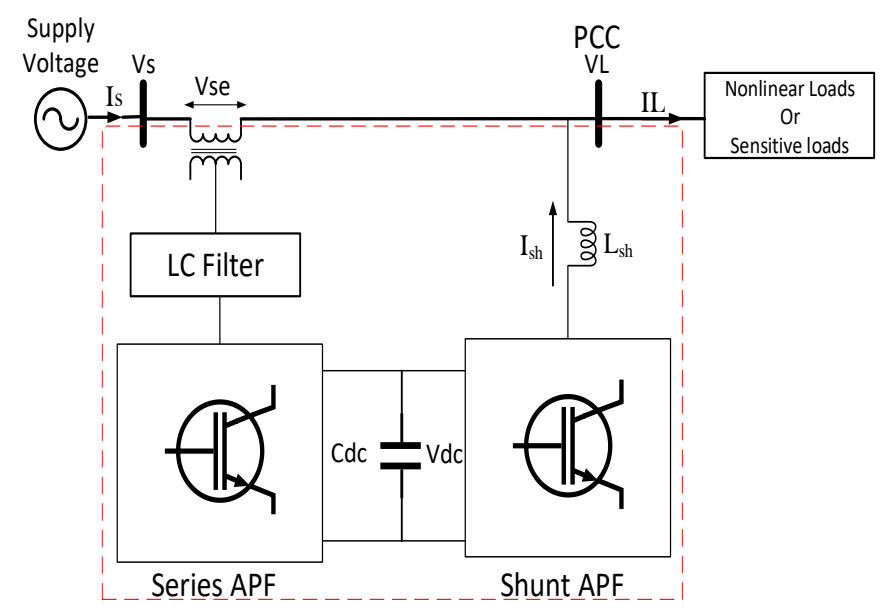

Fig. 1 Schematic of the UPQC.

The functions of shunt inverter are balancing the source currents, injecting the requisite harmonic currents to compensate for harmonics in the load current, injecting the required reactive current to improve the power factor, and regulating the Dc-voltage. Whilst the series inverter works to balance the load voltages via injecting voltage to compensate for voltages in the supply, injecting harmonic voltages to separate the load bus from source voltage harmonics as well as inject the needed active and reactive components to adjust the magnitude of the load bus voltage [3][28].

\section{UPQC CONTROL STRATEGY}

This portion explains the proposed UPQC control technique, which is the amalgamation of series and shunt inverters. A unit vector template generation (UVTG)-based control system is utilized to control both series and shunt APFs [4][7][29]. UVTG-based series inverter control block schematic shown in Fig. 2. The voltage at the load $\left(\mathrm{V}_{\text {Labc }}\right)$ must be balance and sinusoidal with desirable amplitude. An inverter set to a suitable voltage between the PCC and load is used to achieve this goal. Basically, it injects voltages in the opposite direction of the source voltage's imbalance and/or distortion, and these voltages cancel each other out. The load voltage become balanced, preserve desirable magnitude and distortion free [23].

Sensed input source voltage is multiplied by gain equal to $\mathrm{K}=1 / \mathrm{V}_{\mathrm{m}}$ to produce the UVT signal, where $\mathrm{V}_{\mathrm{m}}$ is the fundamental supply voltage's peak amplitude [30]. The phased locked loop (PLL) is used to synchronize with a source voltage and create a phase angle for a voltage $(\omega t)$ that corresponds to phase A [31]. At fundamental frequency, the PLL output is the same as the terminal voltage [5]. The 3phase balanced unit vectors are then generated using this $(\omega \mathrm{t})$ in equation (1) [30].

$$
\left.\begin{array}{c}
V_{a}=\sin (w t) \\
V_{b}=\sin (w t-1200) \\
V_{c}=\sin (w t+1200)
\end{array}\right\}
$$

The reference load voltage signals can be given by multiply desired load voltage magnitude $\mathrm{V}_{\mathrm{Lm}}$ with UVT as follows:

$$
\mathrm{V}_{\text {Labc }}^{*}=\mathrm{V}_{\mathrm{Lm}} \cdot \mathrm{V}_{\mathrm{abc}}
$$

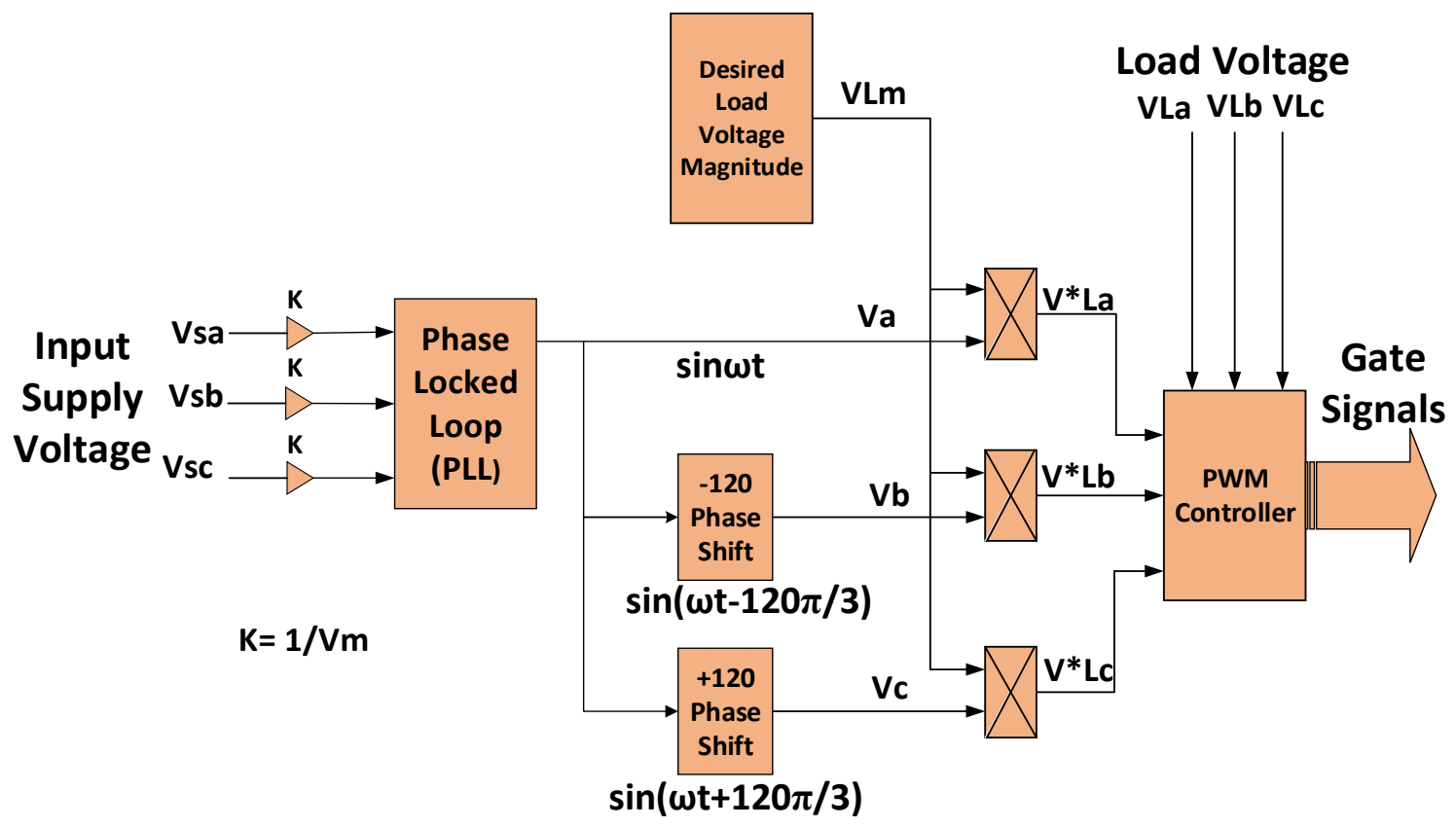

Fig. 2 Series inverter Controller Using the UVTG method 
In order to get distortion-free load voltages, the load voltage must be equal to the reference load voltage. A series inverter's PWM controller compares the reference load voltage $\left(\mathrm{V}_{\text {Labc }}^{*}\right)$ with the actual load voltage $\left(\mathrm{V}_{\text {Labc }}\right)$ to produce switching signals for the IGBT switches.

Fig. 3 illustrates the controlling schematic diagram for a shunt inverter that generates a reference current indicative. UVTG method is used with shunt-inverter to recompense the current harmonics that produced by nonlinear loads. The dclink voltage keeping fixed level, while the shunt inverter compensates the current-harmonics. To accomplish the task, the dc voltage is measured and compared to the reference dc voltage [7][32]. The error is processed by a PI controller, which is employed to maintain a constant dc voltage. The proportional and integral constants were calculated using the Ziegler-Nichols tuning method. PI controller output signal $\left(\mathrm{I}_{\mathrm{m}}\right)$ has been multiplied by UVTG signal to get source current reference signals $\left(\mathrm{I}_{\text {sabc }}^{*}\right)$ as follows:

$$
\mathrm{I}_{\mathrm{sabc}}^{*}=\mathrm{I}_{\mathrm{m}} \cdot \mathrm{V}_{\mathrm{abc}}
$$

This reference signal must be identical to the source current. The actual 3-phase source current $\left(\mathrm{I}_{\mathrm{sabc}}\right)$ is sensed and compared with reference source current signals $\left(\mathrm{I}_{\text {sabc }}^{*}\right)$ in order to obey this reference current signal. After that, a hysteresis current controller with a suitable band processes this error and generates gating switching signals for shunt inverter.

\section{SIMULATION AND DISCUSSION RESULTS}

The suggested control approach was utilized using MATLAB/ SIMULINK. Three-phase, three-wire UPQC has been simulated for sag/swell voltage reduction and voltage/current harmonics elimination using UVTG technique. Table I shows the UPQC system parameters. The source voltage is $(400 \mathrm{~V}, 50 \mathrm{~Hz})$ while the nonlinear load is 3 -phase diode bridge rectifier.

The UVTG control technique is used in three cases for UPQC, as shown below:

\section{A. UPQC Under: Compensation for voltage sag of $30 \%$}

Voltage sag with nonlinear loads has been used to test the operation of UPQC. $30 \%$ of the source's three-phase voltage sag is happened between 0.10 and $0.20 \mathrm{sec}$. In order to maintain the required constant sinusoidal voltage magnitude (harmonic-free) at the load terminals, a difference voltage was injected through the series inverter during sag condition, as shown in Fig 4.

Voltage on the DC link drops when the series inverter injects real power. Figure.5 (a), (b), and (c) illustrate the source-voltage, the compensating and load voltages. Through the use of a series APF, the load voltage remains constant.

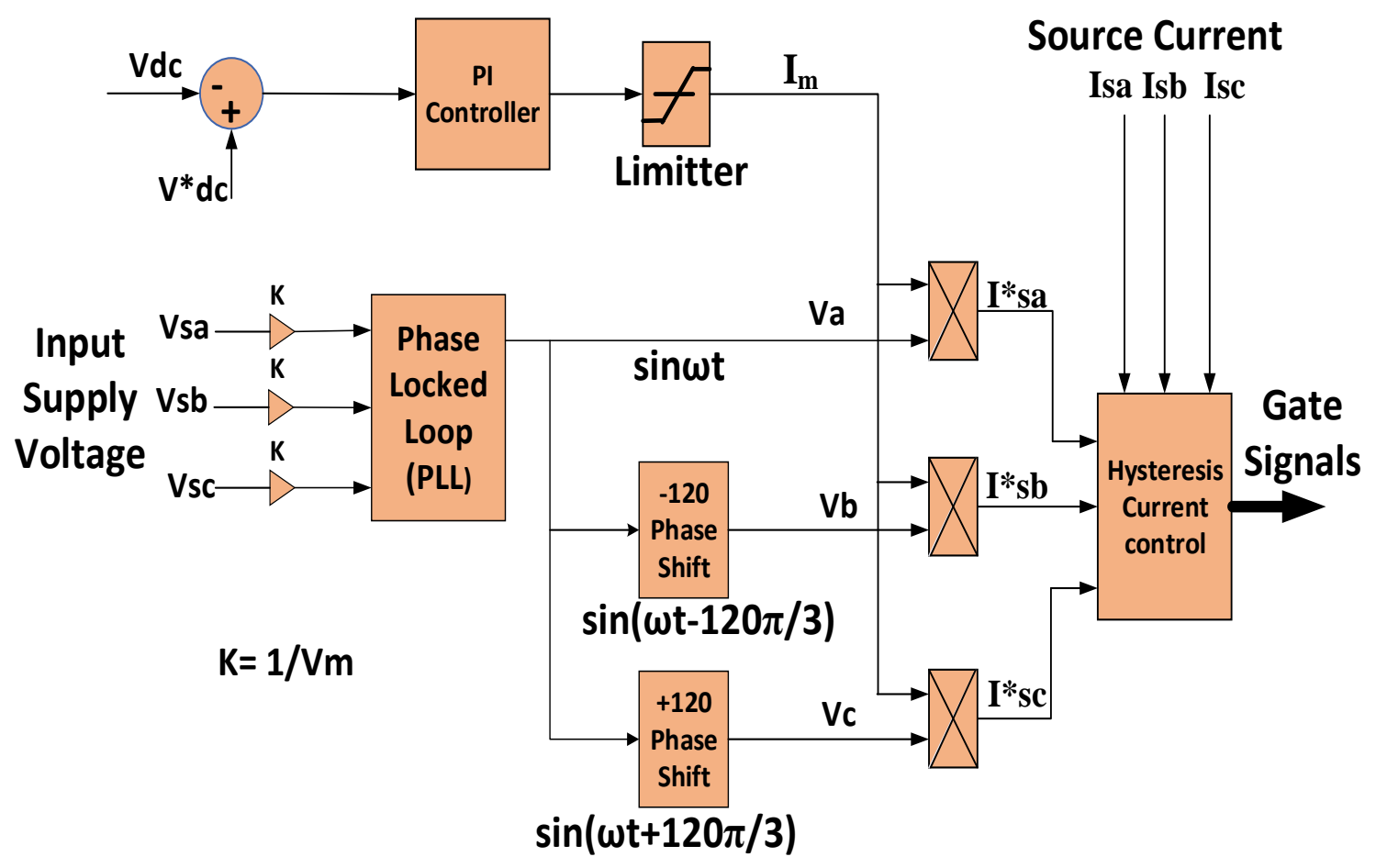

Fig. 3 Shunt inverter Controller based on UVTG technique 
TABLE I

The parameters of UPQC

\begin{tabular}{|c|c|}
\hline Supply & $400 \mathrm{~V}, 50 \mathrm{~Hz}$ \\
\hline DC link & $\mathrm{V}_{\mathrm{dc}}=700 \mathrm{~V}, \mathrm{C}_{\mathrm{dc}}=5000 \mu \mathrm{F}$ \\
\hline Series APF & $\mathrm{L}_{\mathrm{se}}=3 \mathrm{mH}, \mathrm{C}_{\mathrm{se}}=100 \mu \mathrm{F}, \mathrm{R}_{\mathrm{cs}}=5 \Omega$ \\
\hline Shunt APF & $\mathrm{L}_{\mathrm{sh}}=1.6 \mathrm{mH}$ \\
\hline Nonlinear Load & $\begin{array}{c}\text { Diode bridge rectifier in three } \\
\text { phases pursued by R-L load } \\
\mathrm{R}_{\mathrm{L}}=25 \Omega, \mathrm{L}_{\mathrm{L}}=10 \mathrm{mH}\end{array}$ \\
\hline
\end{tabular}
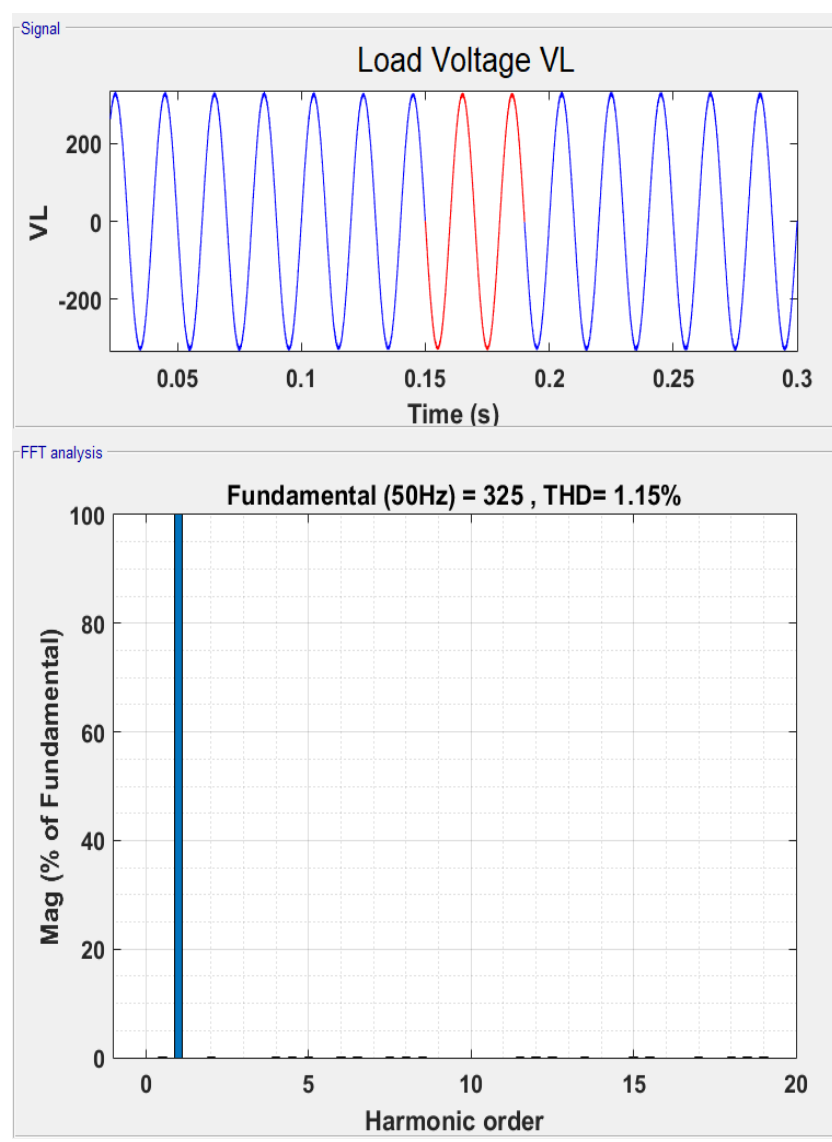

Fig. 4 Frequency spectrum and corresponding load voltage at voltage sag condition.

The series-APF can provide the loads with the real power it needs. When nonlinear loads are connected to a sinusoidal voltage, it draws a current that is not sinusoidal. The non-sinusoidal current includes harmonics that can cause many problems such as the variations in voltage, which may be impact other devices that are connected with network.

The real power is drawn from the grid by the shunt APF, which provides it to the series APF through the dc-link capacitor. To maintain system power balance, the shunt inverter must draw additional current from the grid. Fig.5 (d), shows the increasing in source-current under voltage sag, while Fig. 5(e) and (f) shows the compensating and load currents. As can be seen from Fig 5(g), the dc voltage is kept constant at $700 \mathrm{Vdc}$, where the voltage sag on the source causes a small decrease in dc voltage.
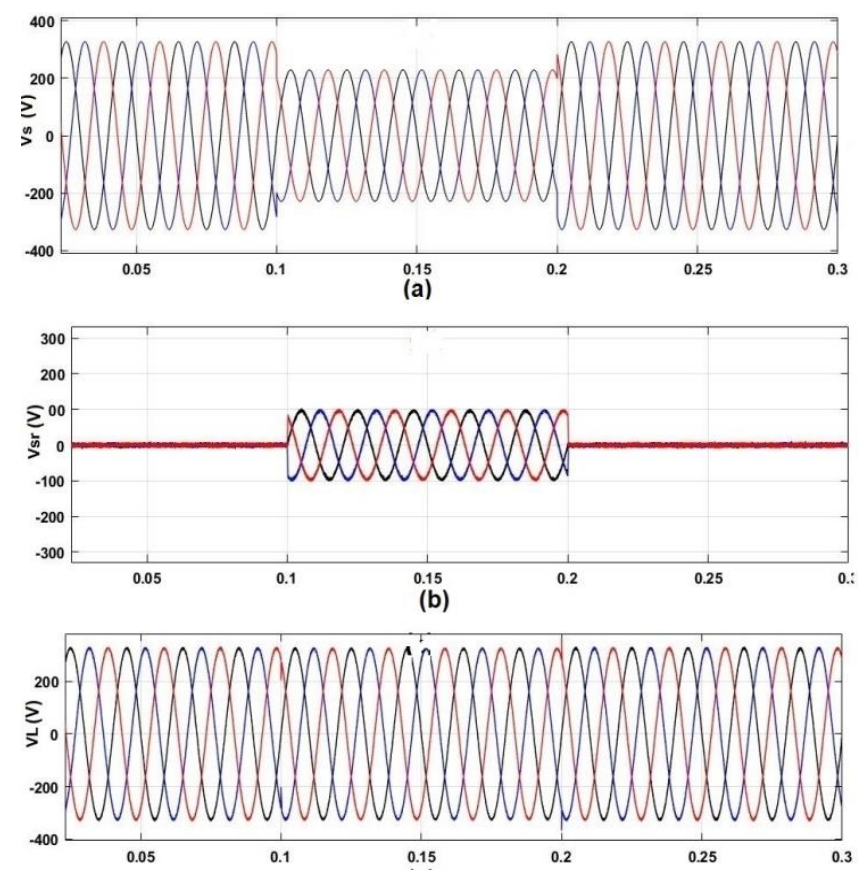

(c)
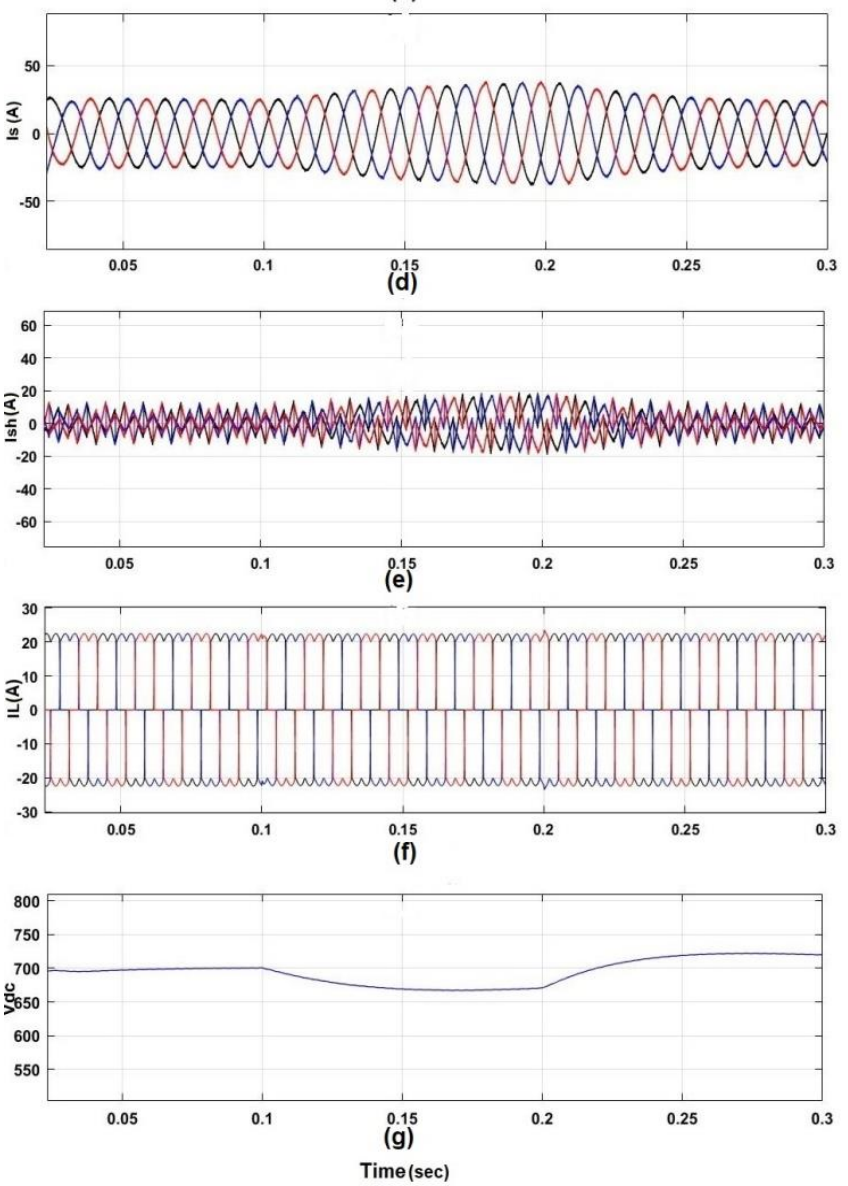

Fig. 5 Simulation consequences of case (A): (a)Supplyvoltage, (b) Compensation-voltage, (c)Load-voltage, (d)Supply-current, (e) Compensation-current, (f) Loadcurrent, (g)DC-link-voltage. 

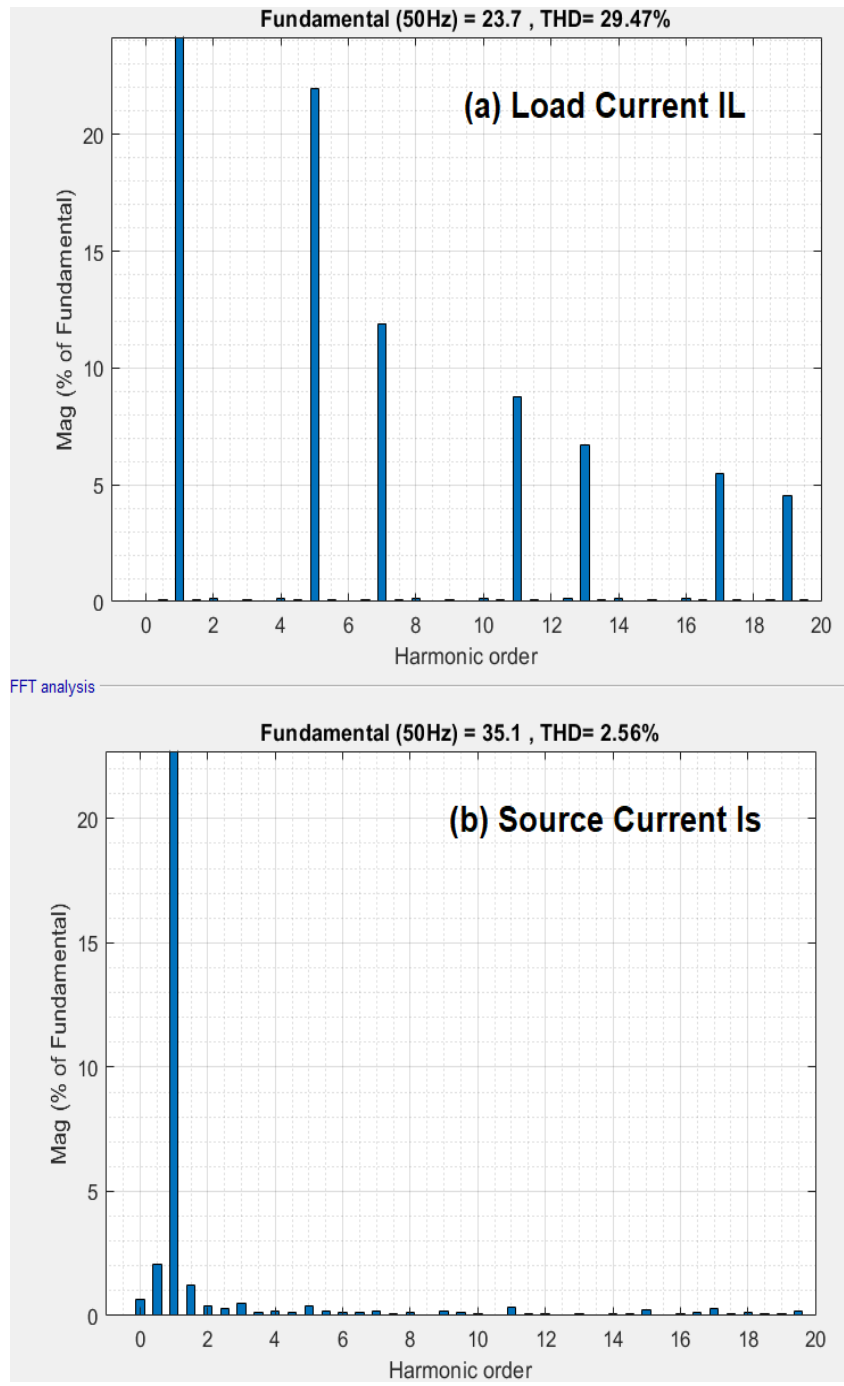

Fig. 6 THD for: (a)Load-current, (b)Source-current, at voltage sag.

As indicated in Fig 4, the THD result for the load voltage is $1.15 \%$. Fig. 6 shows that the THD of the loadcurrent is $29.47 \%$, whereas the THD of the source-current is just $2.56 \%$. The THD is kept within the 5\% limit set by IEEE Standard 519. The shunt APF is utilized to compensate for the current harmonics created by nonlinear loads, and a series APF is employed to maintain a constant voltage at the load with minimal distortion.

\section{B. UPQC Under: Compensation for voltage swell of $30 \%$}

In a system without UPQC, a rise in supply voltage triggers an increase in load voltage, which damages the equipment connected to the system. The operation of UPQC is examined during $30 \%$ of 3-phase source voltage swell which occurs between 0.1 and $0.2 \mathrm{sec}$. Source voltage rise during a voltage swell is depicted in Fig 7 (a). As shown in Fig. 7(c), the series-inverter soaks up the surplus voltage and maintains the load voltage at a fixed free distortion magnitude under voltage swell situation. Source current is reduced in order to restore excess power created by the voltage surge to the supply, as seen in Fig. 7(d). Figure 8 illustrates THD of load-voltage being $1.27 \%$ and the THD of source-current being $3.87 \%$.
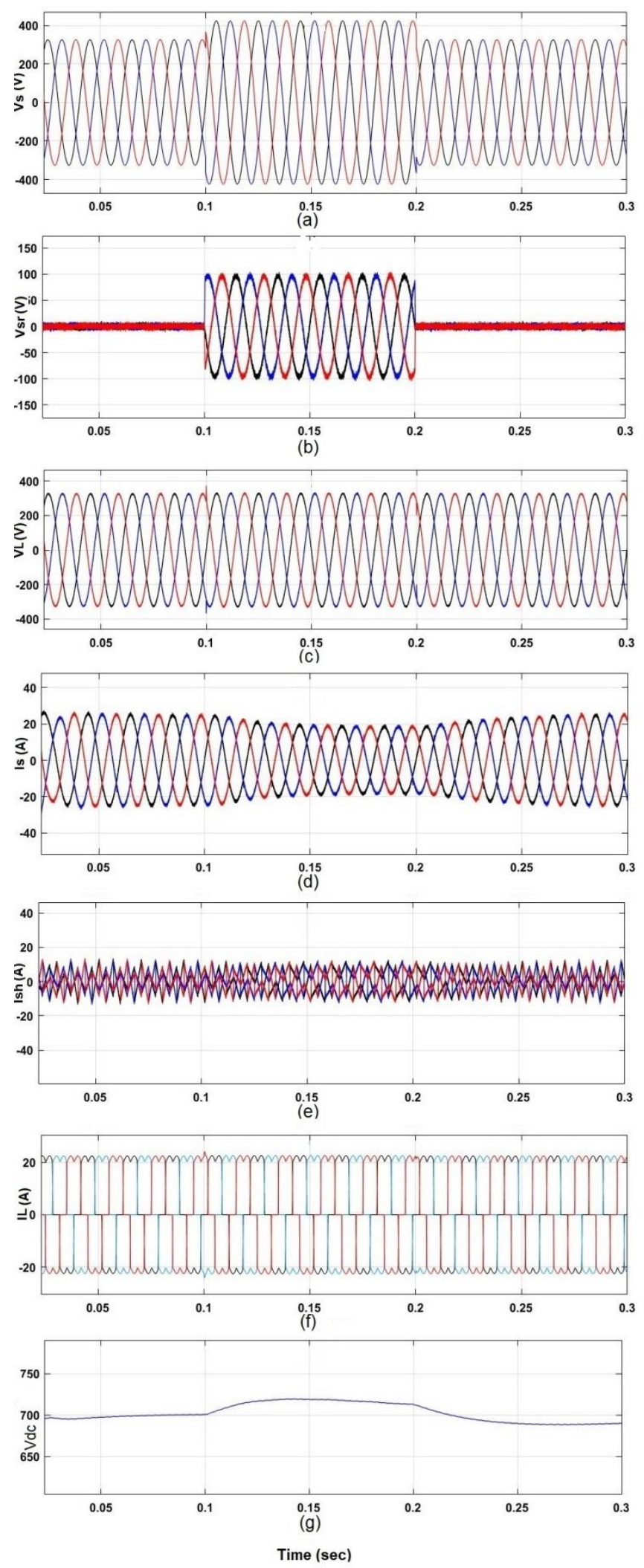

Fig. 7 Simulation consequences of case (B): (a)Supplyvoltage, (b) Compensation-voltage, (c) Load-voltage, (d) Supply-current, (e) Compensation-current, (f) Load-current, (g) DC-link-voltage. 


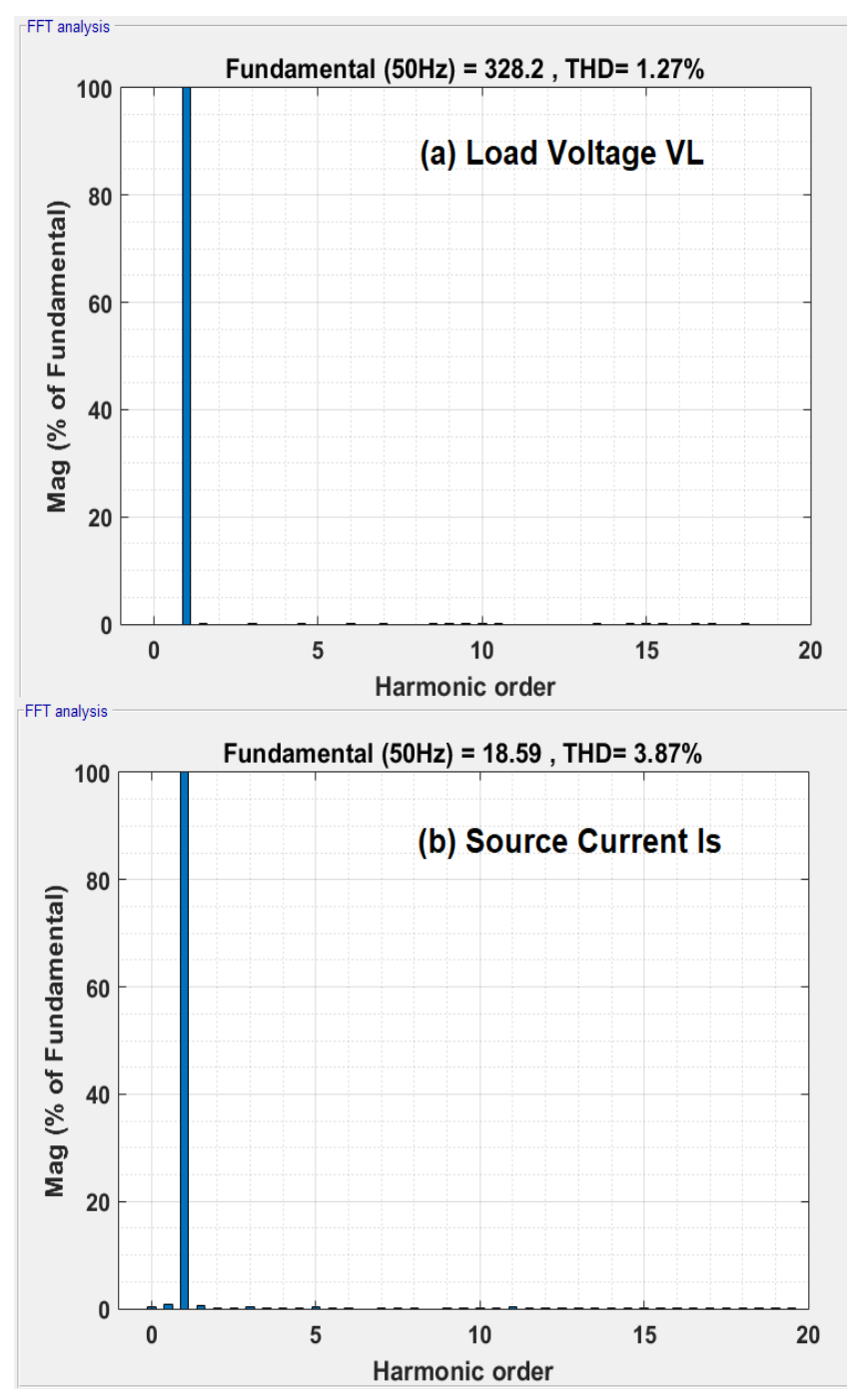

Fig. 8 THD for: (a) Load-voltage, (b) Source-current at voltage-swell.

C. UPQC Under: Voltage harmonics compensation condition.

At time $\mathrm{t}=0.1 \mathrm{sec}$ the source voltage distortion is generated in whole 3 -phase via connecting a 5th (10\% of the essential source-voltage), and 7 th (15\% of the essential source-voltage) in series with main voltage, a harmonic source voltage is used. As shown in Fig. 9(b), the series inverter begins compensating voltage harmonics by injecting the sum of the 5th and 7th harmonics, resulting in distortionfree voltage at nonlinear loads, where Fig. 9 (e) shows the shunt-inverter compensating for current harmonics in order to get distortion-free source current.

As indicated in Fig.10, the THD of load voltage has decreased from $18.04 \%$ to $1.26 \%$, while the THD of source current has decreased to $2.81 \%$ as seen in Fig. 11 .
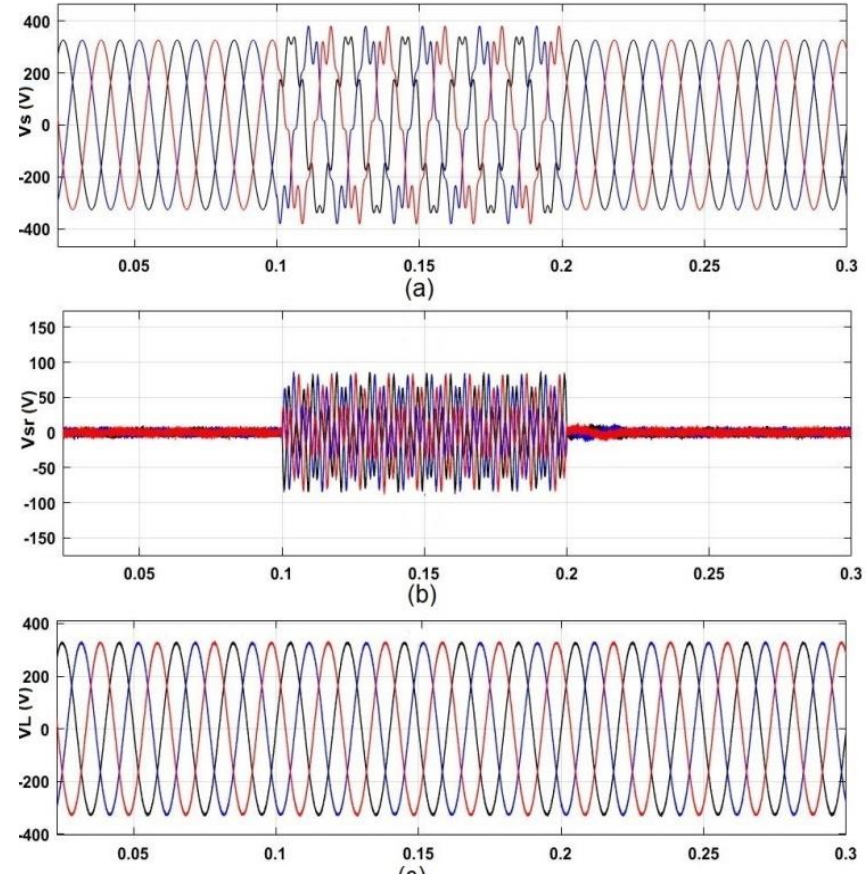

(c)
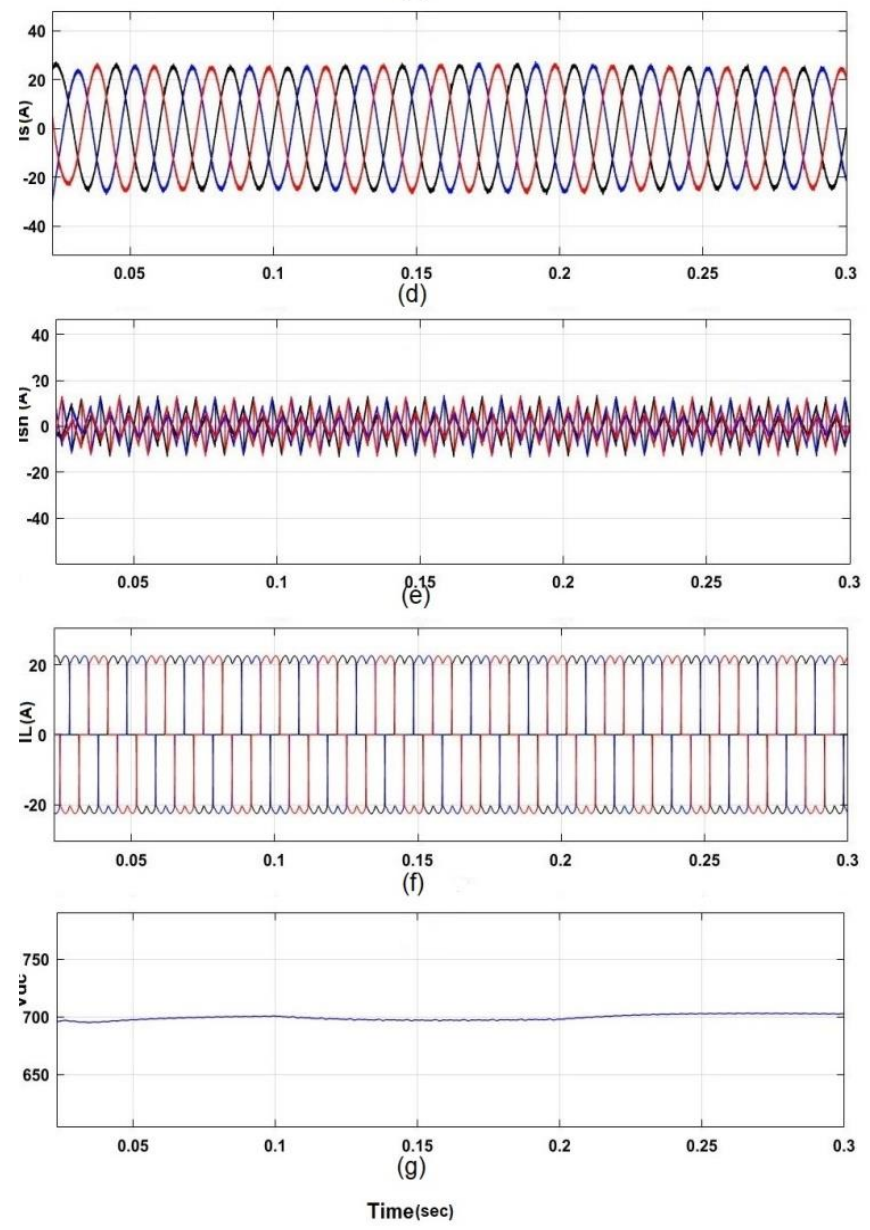

Fig. 9 Simulation consequences of case (C): (a) Supplyvoltage, (b) Compensation-voltage, (c) Load-voltage, (d) Supply-current, (e) Compensation-current, (f) Load-current, (g) DC-link-voltage. 

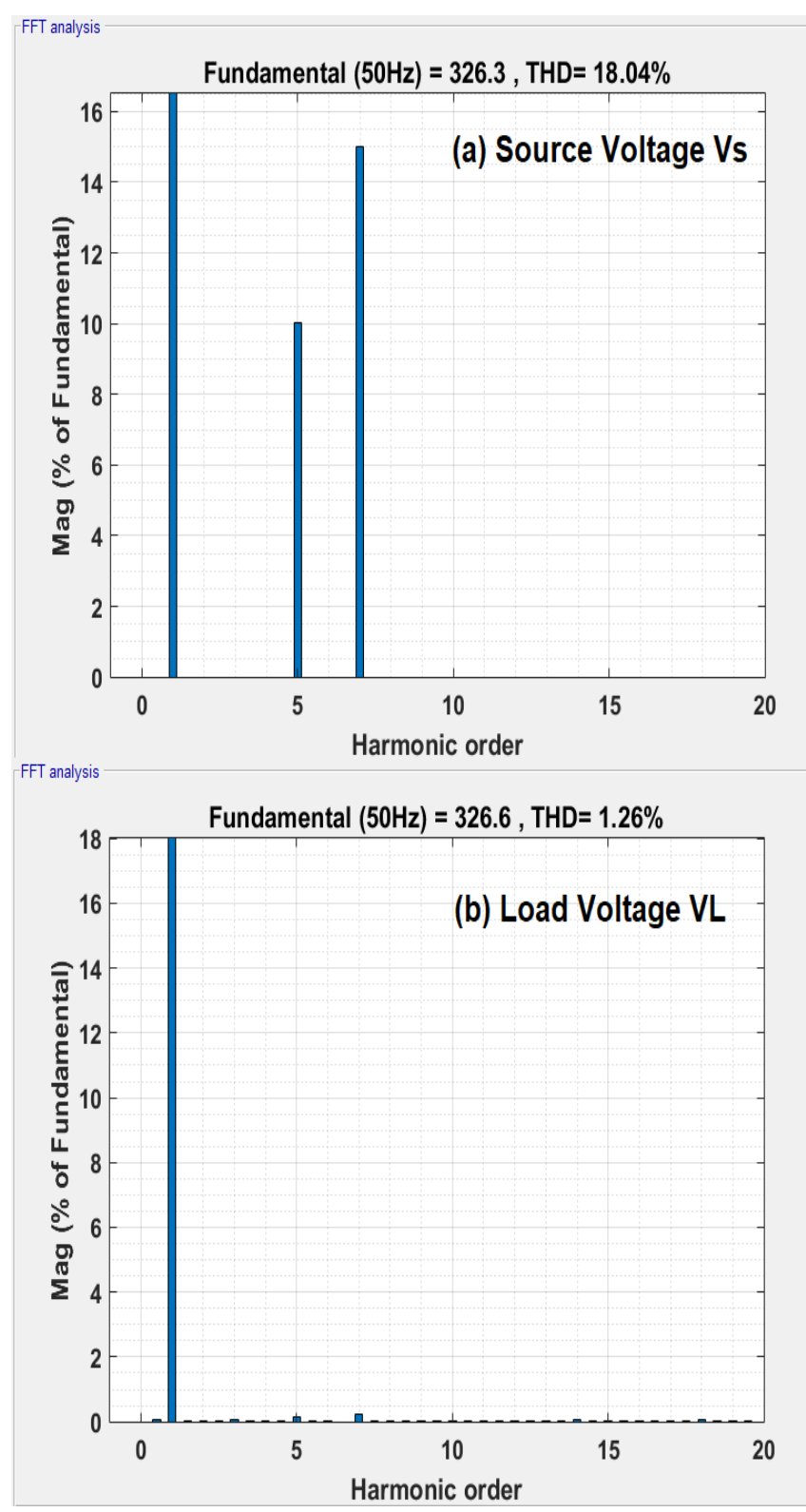

Fig. 10 THD for: (a) Source-voltage, (b) Load-current, at voltage harmonics compensation.

\section{CONCLUSION}

The suggested UPQC scheme is presented in this research. There has been presented a simple UVTG-based control technique. MATLAB/Simulink used to check out the suggested control method's activity. According to the simulation results, the suggested control methodology can successfully compensate for voltage-sag, voltage-swell, and current/voltage harmonics. The source current is unaffected by the nonlinear loads when using UPQC and the waveform became sinusoidal where the source current's THD reduced to 2.81 percent, whilst the THD of load voltage was ameliorated from $18.04 \%$ to $1.26 \%$. The proposed technique was found to sufficiently compensate the load voltage and source current harmonics in order to comply with IEEE Standard 519.

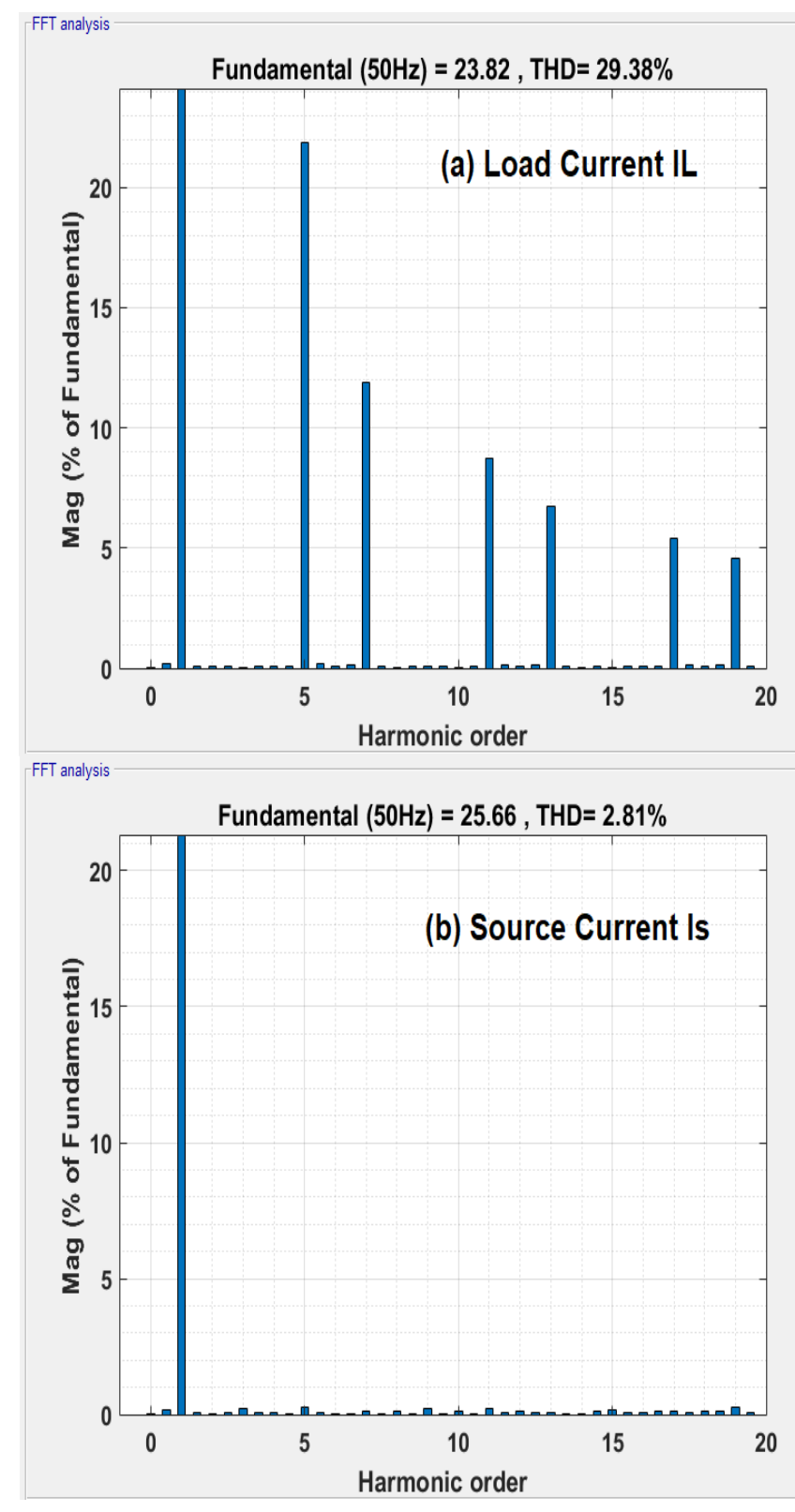

Fig. 11 THD for: (a) Load current, (b) Source-current, at voltage harmonics compensation.

\section{CONFLICT OF INTEREST}

The authors have no conflict of relevant interest to this article.

\section{REFERENCES}

[1] A. N. Alsammak and H. A. Mohammed, "Power quality improvement using fuzzy logic controller based unified power flow controller (UPFC)", Indonesian Journal of Electrical Engineering and Computer Science Vol. 21, No. 1, pp. 1 9, January 2021.

[2] R. Kumar and A. K. Sinha, "Unified Power Quality Conditioner Controller for Enhancement of Power System Voltage Stability using State Vector Modulation" IEEE India Conference (INDICON), pp. 891-896, 2012. 
[3] R. J. Kadam, K. A. Mulani and V.B.Waghmare, "Voltage Distortion at Distribution side reduced by Modified UPQC", in IEEE 3 rd. International Conference for Convergence in Technology, pp. 1-4, 2018.

[4] V. Khadkikar, A. Chandra, A. O. Barry and T. D. Nguyen "Application of UPQC to Protect a Sensitive Load on a Polluted Distribution Network", IEEE Power Engineering Society General Meeting, Montreal, QC, Canada, 2006.

[5] V. Khadkikarl, A. Chandra, A. O. Barry and T. D. Nguyen, "Steady State Power Flow Analysis of Unified Power Quality Conditioner (UPQC)" IEEE International Conference on Industrial Electronics and Control Applications, 2005.

[6] A. Patel and P. Chaturvedi, "Performance of SRFUVTG based UPQCDG for Integration of Solar PV with Non-linear Loads" IEEE International Conference on Power Electronics, Drives and Energy Systems (PEDES), 2016.

[7] S. Shankar, A. Kumar and W. Gao, "Operation of Unified Power Quality Conditioner under Different Situations", IEEE Power and Energy Society General Meeting, Detroit, MI, USA, pp. 1-10, 2011.

[8] H. Fujita and H. Akagi, "The unified power quality conditioner: The integration of series- and shunt-active filters" IEEE Trans. Power Electron., vol. 13, no. 2, pp. 315-322, 1998.

[9] L. F. C. Monteiro, M. Aredes, and J. A. Moor Neto, "A control strategy for unified power quality conditioner", in IEEE International Symposium on Industrial Electronics, Brazil, Jun. 9-11, pp. 391-396, 2003.

[10] M. Yun', W. Lee, H. suh and D. Hyun. “A New Control Scheme of Unified Power Quality Compensator - Q with Minimum Power Injection" The 30th Annual Conference of the IEEE Industrial Electronics Society, November 2 6., Busan, Korea, pp.51-56, 2004.

[11] Y. Y. Kolhatkar, R. R. Errabelli, and S. P. Das, "A Sliding Mode Controller Based Optimum UPQC with Minimum VA Loading", IEEE Power Engineering Society General Meeting, pp. 1-5, 2005.

[12] B. Han, B. Bae, S. Baek, and G. Jang, "New configuration of UPQC for medium-voltage application," IEEE Trans. Power Del., vol. 21, no. 3, pp. 1438-1444, Jul. 2006.

[13] A. K. Jindal, A. Ghosh, and A. Joshi, "Interline unified power quality conditioner," IEEE Trans. Power Del., vol. 22, no. 1, pp. 364-372, Jan. 2007.

[14] V. Khadkikar, and A. Chandra "A New Control Philosophy for a Unified Power Quality Conditioner (UPQC) to Coordinate Load-Reactive Power Demand Between Shunt and Series Inverters" IEEE Transactions On Power Delivery, Vol. 23, No. 4, pp 2522-2534, October 2008.

[15] H. R. Mohammadi, R. Y. Varjani, and H. Mokhtari, "Multiconverter unified power-quality conditioning system: MC-UPQC,’ IEEE Trans. Power Del., vol. 24, no. 3, pp. 1679-1686, Jul. 2009.

[16] Y. Pal, A. Swarup, and B. Singh, "A Comparative Analysis of Three-Phase Four-Wire UPQC Topologies", in IEEE Joint International Conference on Power Electronics, Drives and Energy Systems, 2010

[17] M. Kesler and E. Ozdemir, "Synchronous-ReferenceFrame-Based Control Method for UPQC Under Unbalanced and Distorted Load Conditions', IEEE Transactions On Industrial Electronics, Vol. 58, No. 9, pp 3967-3975, September 2011.

[18] P. E. Melín, J. R. Espinoza, L. A. Morán, J. R. Rodriguez, V. M. Cardenas, C. R. Baier, and J. A. Muñoz, "Analysis, Design and Control of a Unified Power-Quality Conditioner Based on a Current-Source Topology", IEEE Transactions On Power Delivery, Vol. 27, No. 4, pp. 17271736, October 2012.

[19] Shafiuzzaman K Khadem, Malabika Basu and Michael F Conlon "A new placement and integration method of UPQC to improve the power quality in DG network", in IEEE 48th International Universities' Power Engineering Conference (UPEC) Dublin, Ireland, 2013.

[20] A. J. Viji and T. A. Albert Victoire "Enhanced PLL based SRF control method for UPQC with fault protection under unbalanced load conditions" International Journal of Electrical Power and Energy Systems, Volume 58, pp 319-328, June 2014.

[21] M. Hembram and A. K. Tudu, "Mitigation of Power Quality Problems using Unified Power Quality Conditioner (UPQC)", in IEEE third International Conference on Computer, Communication, Control and Information Technology (C3IT), Feb. 2015.

[22] J. Ye, S. B. Gooi and F. Wu, "Optimization of the Size of UPQC System Based on Data-Driven Control Design" IEEE Transactions on Smart Grid, Volume: 9, Issue: 4, pp 1-10, July 2018

[23] S. Lakshmi and S. Ganguly "Energy Loss Minimization with Open Unified Power Quality Conditioner Placement in Radial Distribution Networks Using Particle Swarm Optimization" in IEEE 7th International Conference on Power Systems (ICPS), pp. 55-60, 2017.

[24] S. Lakshmi and S. Ganguly "A comparative study among UPQC models with and without real power injection to improve energy efficiency of radial distribution networks" Energy Systems volume 11, pages113-138 (2020).

[25] T. M. Thamizh Thentral, R. Jegatheesan and K. Vijayakumar, "Unified power quality conditioner with reduced switch topology for distributed networks" Wireless Networks volume 27, pages909-923 (2021).

[26] P. Chaudhary and G. Singh, "Fault mitigation through multi converter UPQC with hysteresis controller in grid connected wind system" Journal of Ambient Intelligence and Humanized Computing volume 11, pages5279-5295 (2020).

[27] M. Rajendran, "Comparison of Various Control Strategies for UPQC to Mitigate PQ Issues" Journal of The Institution of Engineers (India): Series $B$ volume 102, pages19-29 (2021).

[28] Y. N. Bhosale, S. S. Bhosale, U. M. Chavan and S. A. Malvekar, "Power Quality Improvement by Using UPQC: A Review" in IEEE International Conf, on power control, Computing and communication technologies, pp. 375$380,2018$. 
[29] Y. Pal and A. Swarup and B. Singh "Magnetics Supported 3P-3W UPQC for the Realization of Four-Wire Distribution System" in IEEE Fifth Power India Conference, 2012.

[30] V. Khadkikar, P. Aganval, A. Chandra, A.O. Bany and T.D. Nguyen "A Simple New Control Technique For Unified Power Quality Conditioner (UPQC)" in IEEE 11th International Conference on Harmonics and Quality of Power, pp 289-293, 2004.

[31] A. R. Diwan, K. M. Abdulhassan, F. M. Alnahwi “A Fast and Accurate Method for Power System Voltage Sag Detection", Iraqi Journal for Electrical and Electronic Engineering, Vol. 16 | Issue 1 | June 2020.

[32] S. Srinath, M. P. Selvan and K. Vinothkumar, "Comparative Evaluation of Performance of Different Control Strategies on UPQC Connected Distribution System" in IEEE 5th International Conference on Industrial and Information Systems, ICIIS, pp 502-507, 2010. 